\title{
INDUCTIVE AND DEDUCTIVE STRATEGIES OF COGNITION PROCESS IN THE ACADEMIC DISCOURSE
}

\author{
Mariya P. Kotyurova \\ Perm State University, Perm, Russia \\ Lyudmila V. Kushnina \\ Perm National Research Polytechnic University, Perm, Russia
}

\begin{abstract}
The paper deals with the functioning of epistemic situation as a unit of meaning in the academic text in terms of correlation of these units with the main strategies of a cognitive process: inductive and deductive. The epistemic situation includes three interrelated components - ontological, methodological, and axiological. The ontological component is based on scientific knowledge, which represents the content of the academic text. The methodological component unites the methods, ways and techniques of acquiring knowledge; and the axiological component is implemented through various language means, which express the assessment of knowledge received by predecessors or by the text's author. We emphasize that the meaning structure of the academic text has a systematic nature, and its functioning and development are determined by the contradictions between "old" and "new" knowledge, with the text aimed at unfolding the latter one. The paper introduces a statement that text and speech units as text fragments have a circular logical structure formed by alternating inductive and deductive assumptions. This statement is illustrated using modern theoretical texts by prominent Russian linguists. Moreover, the findings are used when analyzing the translated texts of the academic discourse from French into Russian based on the concept of translation space as a synergetic translation model.

Studying the meaning structure lets reveal that its content corresponds to the term system shaping the ontological aspect of knowledge. On the other hand, terms are subordinate to the methodological aspect forming the so-called "protection shield" of the ontological essence of the content. But cohesive meaning units - epistemic situations - may only arise when the axiological aspect is explicitly presented, in particular, when the text is characterized by novelty, argumentativeness, accuracy and significance for the academic community, which reflects the author's discourse individual features.

Key words: academic text, scientific knowledge, text's circular structure, epistemic situation, deductive assumption, inductive assumption, translated discourse, translation space.

Citation. Kotyurova M.P., Kushnina L.V. Inductive and Deductive Strategies of Cognition Process in the Academic Discourse. Vestnik Volgogradskogo gosudarstvennogo universiteta. Seriya 2, Yazykoznanie [Science Journal of Volgograd State University. Linguistics], 2018, vol. 17, no. 1, pp. 172-184. (in Russian). DOI: https:// doi.org/10.15688/jvolsu2.2018.1.18
\end{abstract}

\section{ИНДУКТИВНЫЙ И ДЕДУКТИВНЫЙ ПУТИ ПОЗНАНИЯ В НАУЧНОМ ДИСКУРСЕ}

\author{
Мария Павловна Котюрова \\ Пермский государственный национальный исследовательский университет, г. Пермь, Россия
}

Людмила Вениаминовна Кушнина

Пермский национальный исследовательский политехнический университет, г. Пермь, Россия 
Аннотация. В статье рассматривается функционирование эпистемической ситуации как смысловой единицы научного текста в соотношении с основными путями познавательного процесса - индуктивным и дедуктивным. Эпистемическая ситуация, понимаемая как квант смысла, включает три взаимосвязанных компонента: онтологический, методологический и аксиологический. В основе онтологического компонента лежит научное знание, которое и составляет содержание научного текста; в качестве методологического компонента выступают методы, способы и приемы получения знания; аксиологический компонент реализуется различными вербальными средствами, выражающими оценку, и позволяет определить степень ценности знания, полученного предшественниками или самим автором. Показано, что смысловая структура научного текста имеет системный характер, а ее функционирование и развитие обусловлены наличием противоречий между «старым» и «новым» знанием, для развертывания которого создается текст. Высказывается положение о том, что рече-текстовые единицы как фрагменты текста имеют кольцевую логическую структуру, формируемую чередованием индуктивных и дедуктивных умозаключений. Данное положение проиллюстрировано на материале современных теоретических текстов известных российских лингвистов. На материале переводного научного дискурса с позиций концепции переводческого пространства описано функционирование кольцевой структуры научного текста, являющейся отражением абстрактной эпистемической ситуации. Установлено, что сохранение в тексте перевода индуктивного и дедуктивного путей познания свидетельствует о порождении гармоничного (качественного) перевода, естественным образом вписывающегося в принимающую лингвокультуру.

Ключевые слова: научный текст, научное знание, кольцевая структура текста, эпистемическая ситуация, дедуктивное умозаключение, индуктивное умозаключение, переводной дискурс, переводческое пространство.

Цитирование. Котюрова М. П., Кушнина Л. В. Индуктивный и дедуктивный пути познания в научном дискурсе // Вестник Волгоградского государственного университета. Серия 2, Языкознание. - 2018. - Т. 17, № 1. - C. 172-184. - DOI: https://doi.org/10.15688/jvolsu2.2018.1.18

\section{Введение}

Возможность существования разных подходов к изучению текста представляется бесспорной. Ее обоснование дано многими учеными в таких направлениях, как лингвистика текста, стилистика текста, психолингвистика, социопсихолингвистика, коммуникативная стилистика, идиостилистика, лингвистика перевода и др.

Наличие у них общего объекта - текста, по мнению А.И. Новикова, объясняется его сложностью: «Текст, несомненно, представляет собой сложное образование, которое одновременно включает в себя языковые, логические, речевые, мыслительные, стилистические, экспрессивные и другие компоненты; это цุелостный комплекс языковых, речевых и интеллектуальных фактов в их взаимодействии (курсив наш. - М. К., Л. К.)» [Новиков, 1983, c. 3-4]. Очевидно, что исследователь текста сталкивается с речевой структурой. Этим термином, как обоснованно отмечала М.Н. Кожина, можно обозначить разные явления, поскольку сам процесс, само явление функционирования осуществляется по определенным закономерностям и нормам «строя» речи. Тем самым речевую структуру, которая «остается» в текстах как результат, собственно, только и может исследовать лингвист. То есть речевая структура существует в двояком виде - динамическом и результативном, причем практически доступным исследованию является именно второй (курсив наш. - М. К., Л. К.) [Кожина, 2002, с. 341342]. Мысленно обобщая обширное научное творчество М.Н. Кожиной, мы хотим подчеркнуть его фундаментальный характер, то есть принципиальную устойчивость утверждений, а значит, актуальность теоретических положений (убедительно аргументированных эмпирическим материалом), которые необходимо учитывать в дальнейших современных стилистических исследованиях текста.

\section{Эпистемическая ситуация как единица смысловой структуры научного текста}

Цель данной статьи - рассмотреть функционирование эпистемической ситуации (лаконично описанной ранее на материале русского языка в: [Котюрова, 2011]) как смысловой единицы научного текста в плане ее соотношения с двумя основными путями познава- 
тельного процесса, а именно дедуктивным и индуктивным. Для этого необходимо выявить в контексте данные рече-текстовые единицы и соотнести совокупность этих единиц с терминосистемой текста. Терминосистема создается «под напором» реальной динамичной коммуникативно-познавательной деятельности, трансформируется по правилам логико-семантических отношений терминированных понятий и фиксируется в контексте в основном двумя формально-логическими путями - дедукцией и индукцией. В результате применения правил построения дедуктивных и индуктивных умозаключений формируются текстовые фрагменты с кольцевой структурой. Именно такие фрагменты представляют собой воплощение абстрактной смысловой структуры текста - структуры, ориентированной на когнитивное взаимодействие автора и читателя.

Будем исходить из того, что смысловая структура научного текста чрезвычайно сложна: она имеет системный характер, обусловленный принадлежностью к научному стилю, репрезентация же той или иной смысловой структуры осуществляется под воздействием речевой индивидуальности ученого. На наш взгляд, системность научного текста можно видеть в том, что ему присущи следующие свойства: 1) наличие противоречия, которое является условием функционирования и развития системы (данное свойство системы иллюстрируется ниже); 2) управляемость системы со стороны субъекта деятельности (см. ниже примеры предъявления ипостасей субъекта в тексте); 3) заострение противоречия; 4) дозированное (постепенное, «рассыпанное» по тексту) вмешательство субъекта деятельности; 5) индивидуальный стиль формирования рече-текстовой системы.

При внимательном чтении, акцентирующем интерпретацию метатекстового компонента, мы, несомненно, заметим наличие всех этих свойств рече-текстовой системы - научного текста. Вместе с тем методически целесообразно определить необходимую и достаточную смысловую единицу текста, чтобы в процессе ее функционирования выявить доминирующие (или, напротив, факультативные) свойства этой единицы, способствующие созданию рече-текстовых единиц более вы- сокого ранга, иначе говоря, установить ее текстообразующую функцию.

Целенаправленное чтение научного текста позволяет выявить и определить корпус единиц текста, синтезирующих функции компонентов эпистемической ситуации как смысловой единицы с нечеткими границами, обусловленными полифункциональностью языковых единиц, оформляющих данную ситуацию. Именно в тексте происходят смысловые трансформации: методологически значимая номинация (метод, проблема, исследование, способ, прием, реконструкиия и др.) приобретает онтологическое звучание (Решение этой проблемы направлено...); при таком метонимическом переносе, как исследование проблемы завершено, исследование имеет фундаментальный характер, подчеркивается 'результативность', то есть номинация исследование используется автором в онтологическом смысле; онтологически значимые компоненты выполняют методологическую функцию (например, словообразование, реконструкция компонентов словосочетания); методологически определенной номинации придается аксиологическая ориентация (В работе решена проблема профориентации в иколе) - подчеркиваются аксиологические нюансы 'необходимость, актуальность, трудность'. Рассматривая соотношение этих единиц в целостной рече-текстовой картине, можно установить, что они, в свою очередь, формируют рече-текстовые единицы - фрагменты текста - более высокого ранга, нередко имеющие кольцевую структуру (в данном случае именно это и важно, что у кольца начало и конец смыкаются). Такие фрагменты текста имеют логическую структуру чередующихся дедуктивных и индуктивных умозаключений, а именно Д-И...Д; Д - И... - Д и т. д. (с вполне возможными отклонениями от строгого порядка). Например: Рассмотрение вопроса о соотношении лингвистики текста и стилистики (Д) - формирование лингвистики текста (И) - с более ранним развитием стилистики (в ее функциональном аспекте) (И) - стилистический аспект текста (И) - не означает специиального рассмотрения вопроса о соотношении стилистики и лингвистики текста (Д) (Кожина, 2015, с. 6). Такие более сложные, целостные (статические) фрагменты текста со- 
относятся с динамической природой научно-познавательной деятельности, природой, проявляющейся в построении дедуктивных и индуктивных умозаключений. Естественно, что построения логических (абстрактных) умозаключений - дедуктивных и индуктивных - трансформируются в речи / тексте, поэтому требуют углубленного проникновения в его смысловую структуру. Именно обобщенно-отвлеченный взгляд на совокупность / корпус эпистемических ситуаций как смысловых единиц позволяет установить наличие дедуктивного и индуктивного путей научного познания, зафиксированных в каждом научном тексте.

\section{Противоречие}

\section{«старого» и «нового» знания в научном тексте}

Как было сказано выше, речевой системе, представленной в виде научного текста, присуще наличие противоречия, которое является условием функционирования и развития системы. Рассмотрим фрагменты текстов, в которых зафиксировано противоречие между «старым» знанием, актуальным в качестве общепринятого, традиционного либо полученным предшественниками, но еще не вошедшим в общий научный фонд, дискуссионным, и «новым» знанием (знанием автора), для развертывания которого и создается определенный текст. К наиболее типичным маркерам относятся: как известно / хорошо известно / всем известно, что; идеи $N$ - на наш взгляд / по нашему мнению / с нашей точки зрения и многие другие, нередко индивидуально выдвинутые либо завуалированные контекстом. В качестве иллюстративного материала используем современные теоретические тексты известных лингвистов А.В. Бондарко (2002), М.Н. Кожиной (2015) и Н.К. Рябцевой (2005) и подчеркнем в этих контекстах речевые единицы, обозначающие противоречия.

Речь идет не только о дифференциации внутри широкой сферы семантического содержания (старое. - M. К., Л. К.) - но и об анализе взаимосвязей разных сторон семантики как сложного целостного объекта (новое. $-M$. К., Л. К.); На наш взгляд, именно осмысление взаимодействия различных аспектов и уровней изучаемого содержания является необходимым основанием для постановки воп- роса о семантике как целостной системе, имеющей определенную структуру (новое. $-M$. K., Л. К.) (Бондарко, 2002, с. 99); Существует широкое истолкование понятия «грамматическая категория», встречающееся как в языковедческой традиции (стаpoe. $-M$. К., Л. К.), так и в современной литературе» - ...в настоящее время представляется целесообразным более строгое истолкование (новое. M. К., Л. К.) рассматриваемого понятия (Бондарко, 2002, c. 205-206);

...все очевиднее обнаруживается актуальность изучения проблем функционирования языка (новое. $-M$. . ., Л. $K$.) - ...как известно, закономерно развивается и особая отрасль языкознания, получившая название лингвистики текста (ЛТ) (стаpoe. - М. К., Л. К.) (Кожина, 2015, с. 5);

...стала возможной благодаря развитию концептуального анализа (далее следует уточнение, раскрытие терминированного понятия концептуального анализа, перед которым был бы уместным (коммуникативно целесообразным) сигнал - союз то есть. - M. К., Л. К.), углубленного семантического и функционального исследования представлений и понятий, сформировавшихся в языке и языком - ...ориентация новой лингвистики на субъекта речи... (новое. $-M$. К., Л. К.) и возрождение интереса к идеям В. Гумбольдта, Б. Уорфа и Э. Сэпира и др. относительно языковой картины мира, долгое время остававшимся на периферии лингвистики и в свое время почти не получившим признания (старое. - M. К., Л. К.) (Рябцева, 2005, с. 57).

Учитывая ограниченные возможности жанра статьи, обратим особое внимание на то, что рассуждению о противоречии, выявленном автором того или иного приведенного текста, присущи все вышеперечисленные признаки речевой системности. Из приведенных примеров видно, что противоречие с необходимостью присуще содержанию каждого научного текста, причем, как показывает анализ материала, в теоретическом тексте противоречие обычно эксплицируется особенно ярко. Важно отметить, что именно с этой целью автор, управляя речевой системой, отбирает - с учетом собственной, то есть индивидуальной, точки зрения - из языковой системы различные языковые единицы, которые, подчеркнем, по воле автора приспосабливаются к данной познавательно-коммуникативной задаче и в результате по праву употребляются в тексте. Как видим, в научном теоретическом тексте действительно проявляются перечисленные выше свойства, присущие рече-текстовой системе. 
Само противоречие в тексте выражено описательно, посредством различных сопоставлений таких номинативно-содержательных единиц, как термины, общенаучные слова (слова широкой семантики) и другие абстрактные лексемы. Маркеры же служат лишь «сигналами» о наличии данной познавательной ситуации. В рассматриваемом отношении важно, что в тексте эксплицирован вполне определенный познавательный смысл (эпистемическая ситуация) 'противоречие'. Эпистемическая ситуация - это единица содержания научного текста. Содержанием научного текста является научное знание (в пер. с греческого «эпистема»); в соответствии с таким - деятельностным, научно-познавательным, по существу, «знаниевым» - подходом абстрактная, то есть отвлеченно-обобщенная, единица смысловой структуры научного текста и получила название эпистемической ситуации. Эта единица объединяет разноплановые компоненты, представляющие содержание, или онтологию, а также метод, способ, приемы получения знания, его познавательную форму (понятие, суждение, умозаключение, утверждение, вопрос, гипотезу, концепцию, теорию, закон), иначе говоря, методологию получения знания, по природе включающего логическое мышление, иногда становящееся автоматическим, даже, можно сказать, «конвейерным».

Нас убеждает точка зрения, существующая в области психологии научного познания: строго формально-логическое движение мысли человека не приводит к получению нового знания. Собственно логическое мышление, становясь конвейерным, осуществляется «по накатанному пути», без препятствий, без противоречий, благодаря преодолению которых только и развивается, то есть расширяется и углубляется, научное знание. Несомненно, эпистемическая ситуация представляется явно неполной, коммуникативнопрагматически неясной, если в ее описании не выражена аксиологическая ориентация читателя (потребителя) в степени ценности знания, полученного предшественниками или самим автором.

Функционально-стилистические исследования научного текста свидетельствуют о неадекватности, а именно об асимметрии, текста и его содержания - репрезентированного научного знания. На наш взгляд, причина неадекватности заключается в том, что знание в тексте представляется одновременно в двух ипостасях - в результативной (статической) и деятельностной (динамической). Причем сугубо познавательный (деятельностный) аспект при порождении текста управляется коммуникативно-прагматическим, peзультативным: научное знание фиксируется автором в виде готового (а не получаемого) продукта. Ранее нами было предложено рассматривать научное знание с учетом его результативности как зафиксированную в тексте эпистемическую ситуацию - смысловую единицу научного текста [Котюрова, 1988]. Этот квант, сгусток смысла разного объема представляет собой единство трех взаимосвязанных компонентов: онтологического ( $\underline{\mathrm{O}}$ - предмет рассмотрения; выделено подчеркиванием), методологического (М - метод, способ, прием рассмотрения; выделено полужирным курсивом), аксиологического ( $A$ - актуальность, ценность, важность полученного знания; выделено светлым курсивом). Кстати, порядок представления этих сторон может быть различным.

См., например, в тексте Н.К. Рябцевой: благодаря развитию концептуального анализа, углубленного семантического и функционального исследования представлений и понятий, сформировавшихся в языке и языком - AMO; в тексте А.В. Бондарко: именно осмысление (М) взаимодействия различных аспектов и уровней изучаемого содержания $(\mathrm{O})$ является необходимым основанием (М) для постановки вопроса (A) о семантике $(\mathrm{O})$ как целостной системе, имеющей определенную структуру (М) - МОАОМ; в тексте М.Н. Кожиной: актуальность изучения проблем функционирования языка - АМО.

В научном тексте представлена совокупность разнообразных частных, или индуктивных, смысловых единиц - эпистемических ситуаций. Эти единицы «рассыпаны» по тексту, поэтому «дозированно» эксплицируют знание. В силу притяжения однородных компонентов смысла по крупицам формируется целостное знание - статическое содержание научного текста. 


\section{Терминосистема в ее отношении} к эпистемической ситуации

Изучение смысловой структуры научного текста показывает, что его содержание соотносится с терминосистемой. Здесь мы обратим внимание на то, что в контексте термины как представители онтологического аспекта знания обусловлены содержательной беспредельностью в микро- и макроотношении. В связи с этим термины постоянно пребывают в состоянии подчинения избранному подходу, методу, приемам исследования, таким логическим операциям с абстрактными научными понятиями, как уточнение, усиление, ограничение, добавление, присоединение и др. Все эти методологические ментальные операции формируют «защитную оболочку» онтологической сущности содержания речи - сущности не только крайне абстрактной, но и совершенно непредсказуемой для читателя. Защитная (и в то же время «менеджерская») функция методологического аспекта эпистемической ситуации чрезвычайно важна в научном тексте, так как управляет принципиально познавательной, «вперед смотрящей», совместной деятельностью автора и читателя. Действительно, четко сформулированное описание предмета исследования «защитит» автора от вопроса «что рассматривается?», а также претензий типа «не рассмотрено», «не определено» и т. п.

Не менее важной является функция речевых единиц, выражающих аксиологический аспект эпистемической ситуации. Такие единицы непосредственно ориентированы на помощь читателю в оценке сообщаемого знания, в частности его новизны, аргументированности, достоверности, ценности для научного сообщества и других достоинств знания, полученного предшественниками и самим автором. Средства выражения оценки способствуют активному взаимодействию с читателем и, значит, прежде всего, взаимопониманию: автор передает свою мысль не индифферентно, равнодушно, констатирующим образом, но с горячим интеллектуальным чувством радости от открытия (пусть малого!), которое особенно ценно перспективой для дальнейшего изучения беспредельной действительности. Специальному исследованию рациональной оценки в научном тексте посвя- щен ряд работ; назовем здесь одну из последних, выполненную в традициях Пермской научной школы проф. М.Н. Кожиной, - «Роль оценки в механизме развертывания научного текста» [Данилевская, 2005].

Обобщая, важно подчеркнуть, что только при условии привлечения, притяжения компонентов методологического и аксиологического аспектов знания терминосистема научного текста формирует целостные смысловые единицы - эпистемические ситуации. Эти единицы обычно эксплицированы в полном объеме, то есть в единстве трех компонентов либо двух «личностных» - методологического и аксиологического.

\section{Кольцевая структура смысла научного текста как условие формирования дедуктивной эпистемической ситуации}

Любой путь познания предполагает наличие субъекта познавательной деятельности, понимаемого как совокупность свойств, объединенных социальными и индивидуальными компонентами. При этом субъект (автор текста) предстает перед читателем - условно - в разных ипостасях: прежде всего, в качестве констатирующего владельца «старого» знания (соотнесем этого владельца с Наблюдателем - идея Е.В. Падучевой [Падучева, 2006]), кроме того, в качестве владельца «нового», авторского знания и, наконец, в качестве субъекта познавательной деятельности, понимаемой как процесс в условиях, «очищенных» от реальной познаваемой действительности, иначе говоря, в качестве субъекта с акцентом на его социальном компоненте, соответствующем логико-смысловым отношениям понятий. Бесспорно, в научной речи / тексте неизбежно проявляются такие личностные характеристики субъекта коммуникативно-познавательной деятельности (обобщенно - автора), как индивидуальный познавательный стиль, стиль мышления ученого, его речевая индивидуальность (см. об этом: [Котюрова, Тихомирова, Соловьева, 2011]). При внимательном, тем более исследовательском, чтении, то есть при восприятии в речи, в процессе действительного функционирования, эти единицы осознанно 
или неосознанно объединяются, подчиняясь доминирующим вышестоящим смыслам. Целеустремленное чтение может обеспечить понимание содержания текста, формирование смысловой структуры текста, а также проникновение в индивидуальную когнитивную сферу автора.

«Спаянность» ипостасей автора позволяет дифференцировать их лишь условно:

1) Наблюдатель, констатирующий, утверждающий предшествующее, известное, фоновое для автора и читателя знание: $\mathrm{Ka}$ тегориальные значения лежат в основе граммем - членов грамматических категорий (Бондарко, 2002, с. 248); Аспектуальные значения воздействуют на характер временных отношений между действиями, оказывая влияние на их существенные свойства (Бондарко, 2002, с. 509); Проблемы жанра, обычно так или иначе в связи с проблемой стиля, широко представлены в литературе (Кожина, 2002, с. 155); Любопытство становится этически маркированным и социиально осуждаемым поведением, когда оно направлено на другого человека (Рябцева, 2005, с. 309). Повидимому, вслед за А.В. Бондарко, трактовку «области скрытой грамматики» [Бондарко, 2002, с. 253] можно распространить на научный текст и считать, что в любом фрагменте научного текста (предложении, абзаце, более сложном компоненте, целом тексте) субъект-наблюдатель представляет собой скрытую (имплицитную) категорию, однако может быть выявлен и эксплицирован посредством глаголов со значением бытия, существования, наличия;

2) субъект деятельности, выдвигающий логический, то есть социально принятый, конвенциональный компонент познавательного процесса: Наиболее распространены три понимания термина текст: 1)... ; 2) ...; 3)... Подобное толкование текста находим и в работах лингвокультурологического направления... (Кожина, 2002, с. 18); ...в форме бинарной классификации, в которой выделяются две ступени. Первая ступень... Вторая ступень... Обе ступени данной бинарной классификации основаны на одном и том же признаке коррелятивности, однако каждая ступень характеризуется особым отношением к этому признаку (Бондарко, 2002, с. 210); Научное познание оказывается обусловленным... факторами, способными предопределять своеобразие национальной науки. Наиболее ярко оно проявляется при сопоставлении античной, современной западной и традицчионной восточной науки (Рябцева, 2005, c. 191). Не случайно в стилистической литературе одной из первых была зафиксирована, определена, рассмотрена и описана такая особенность научного текста, как логичность речи (см.: подчеркнутая логичность - термин М.Н. Кожиной, открытая логичность - термин А.Н. Васильевой);

3) субъект индивидуальной когнитивной и текстообразующей деятельности: Bместе $c$ тем нельзя исключить и возможность использования двухступенчатой классификацчии. Фактически и в ней представлены все три типа грамматических категорий (Бондарко, 2002, с. 211); Не разделяя одни из указанных позиций (отождествление стиля $и$ жанра, понимание жанра как части или формы стиля), следует согласиться с другими. Например, с бесспорной взаимосвязью и взаимодействием стиля и жанра, их единством, представленным в реальности речи. Конечно, стиль... проявляется так или иначе в произведениях различных жанров (этого писателя, направления). Однако и требования каждого жанра обусловливают соответствуюший стиль... Вернее все же считать, что жанр определяет стилевые особенности речи... Таким образом, стиль и жанр - это взаимосвязанные компоненты художественного иелого, каждый со своим назначением (Кожина, 2002, с. 157-158); Человеческое мышление принципиально проспективно - обращено к будущему. <..> Идея будущего в первую очередь связана с воображением... Будущее всегда в большей или меньшей степени неопределенно... Представить будущее помогает устройство мира, иикличность природного времени... Подробно и в другом аспекте проблема будущего затрагивалась в Главе 4. Здесь же отмечаются наиболее важные ее составляющие, имеющие непосредственное отношение кментальной сфере (Рябцева, 2005, c. 274-276). Как видим, речевая индивидуаль- 
ность автора текста наиболее ярко проявляется посредством выражения оценочности.

Анализ текстов показывает, что все ипостаси автора представлены в любом научном тексте, вопрос лишь в степени их выдвижения (актуализации) в целом произведении. При анализе текстов важно учитывать доминирующую в них совокупность средств, ориентированных на выражение тех или иных свойств субъекта / автора. Именно доминирование определенных совокупностей рече-текстовых единиц, испытывающих функционально-смысловое притяжение, является необходимым условием формирования / установления особенностей текстообразования в плане речевой индивидуальности ученого.

Рассмотрение этих смысловых единиц в динамике научно-познавательной деятельности (с учетом установки познающего субъекта) позволяет обнаружить кольцевую структуру смысла научного текста, проявляющуюся, как мы уже указывали, в движении от общего утверждения (дедуктивного), дифференцированного на целый ряд частных (индуктивных), которые далее подвергаются обобщению, в результате которого, в свою очередь, формируется дедуктивная эпистемическая ситуация. Важно подчеркнуть, что такое схематичное описание познавательной структуры текста вполне может соответствовать лишь одному - иерархическому - типу связей эпистемических ситуаций. Реальные тексты могут иметь сложную, «запутанную» смысловую структуру, если смысловые единицы «не соблюдают» логико-семантических правил следования и связи, вторгаются в «чужое» пространство, нарушают общепринятый (потому предсказуемый) порядок движения мысли читателя. Как будет показано ниже, выявленные закономерности релевантны при порождении переводного дискурса, где в качестве познающего субъекта выступает переводчик, что обусловливает дедуктивно-индуктивную структуру смысла научного текста.

В свете всего сказанного о таких смысловых единицах научного текста, как эпистемические ситуации и их совокупности, следует особо отметить, что и те, и другие формируются (как автором, так и читателем) не на случайной смысловой основе, а на эпистемической, научно-познавательной, имеющей свою конеч- ную цель - создание стройной, гармоничной терминосистемы текста, доступной восприятию читателем. Значит, во главе (или, наоборот, в фундаменте) познавательного «треугольника» эпистемической ситуации расположен термин (терминированное понятие) как онтологический компонент. Вместе с тем источником и движущей силой при формировании данной смысловой единицы служит субъект. В таком случае субъект проявляется посредством выражения двух других компонентов эпистемической ситуации - методологического и аксиологического. Эти компоненты, в обобщенно-познавательном отношении имея факультативный, дополнительный характер, в коммуникативном же представляют собой совершенно необходимое сопровождение, можно сказать, ту «одежку», по которой встречают «гостя».

По нашим наблюдениям, эпистемическая оболочка (в работах Т.М. Николаевой «эпистемический кортеж») совершенно необходима, она по природе присуща терминам в терминосистеме текста, поэтому легко вычленяется из контекста.

Приведем примеры (о принципах маркировки компонентов см. выше):

Цельій текст как объект стилистики текста; 8 вопросе изучения текста как объекта лингвистического исследования; становится объектом стилистики; общий объект исследования в лингвистике текста и в функциональной стилистике; особая отрасль языкознания, получившая название лингвистики текста (ЛТ); мысль о иленении текста на синтаксические целье; лингвистики текста как особого направления языкознания; теории текста; имеем в виду функциональную стилистику, или, иначе, науку о функциональных стилях (Кожина, 2015);

Теория значения в системе функциональной грамматики; вопрос о значении и смысле рассматривается на основе того взгляда на проблему стратификации семантики, которого я придерживаюсь в настоящее время; именно осмысление взаимодействия различных аспектов и уровней изучаемого содержания является необходимымм основанием для постановки вопроса о семантике как целостной системе, имеющей определенную структуру; Идея стратификации семантики; на двух основных аспектах семантического содержания - значении и смысле; Вопрос о соотношении значения и смысла связан с проблемой «эквивалентности при существовании различия» (Бондарко, 2002); 
Ориентация новой лингвистики на субъекта речи, сознания, культуры, знания и поведения; Концептуальный анализ - новое ... направление влингвистике, принципиально конструктивное и ставшее к началу XXI в. магистральным (Рябцева, 2005).

\section{Реализация}

\section{индуктивно-дедуктивной структуры в переводном научном дискурсе}

Понятие эпистемической ситуации, разработанное М.П. Котюровой и Е.А. Баженовой, апробировано нами на материале русскоязычного научного текста / дискурса. Однако стратегия анализа научного текста с опорой на данное понятие носит универсальный характер, что было выявлено нами при исследовании переводного дискурса [Котюрова, 2011, 2013, 2014; Котюрова, Баженова, 2007; Котюрова, Соловьева, 2017].

В основе наших рассуждений лежит концепция переводческого пространства, исходные положения которой сформулированы в [Кушнина, 2009; Введение ..., 2014] и получили дальнейшее развитие как в трудах автора концепции, так и в работах его учеников и последователей.

Суть концепции переводческого пространства сводится к следующему. Перевод как любая сложная система имеет свою структуру. Это структура нелинейной конфигурации, организованная в виде пространственно-временного континуума, который обозначен как переводческое пространство, формирующееся вокруг содержания текста оригинала и включающее содержание текста перевода. Каждый элемент переводческого пространства образует свою полевую структуру смысла - поле. В переводческом пространстве выявлено три поля субъектов переводческой коммуникации (автора, переводчика, реципиента) и три текстовых поля (содержательное, энергетическое, фатическое). В каждом поле переводческого пространства формируется уникальный смысл, при этом интегральный смысл целого текста перевода является не их суммой, а результатом синергии: модальный смысл поля автора, индивидуально-образный смысл поля переводчика, рефлективный смысл поля реципиента, фактуальный смысл содержательного поля, эмотивный смысл энергетического поля, лингвокультурологический смысл фатического поля. Кроме того, каждое смысловое поле имеет свой источник: предтекст в поле автора, подтекст в поле переводчика, контекст в поле реципиента, текст в содержательном поле, затекст в энергетическом поле, интертекст в фатическом поле. Результатом перевода является синергия смыслов всех полей переводческого пространства, что сопровождается приращением новых смыслов и их вхождением в принимающую культуру. Качественный перевод обозначен в данной концепции как гармоничный, что отражает гармоничное переводческое мировоззрение и что обусловливает естественное вхождение текста перевода в новую языковую и культурную среду. В случае некачественного перевода, то есть если текст содержит переводческие ошибки, погрешности, несоответствия, он признается дисгармоничным.

Концепция переводческого пространства была апробирована на материале текстов и дискурсов, принадлежащих различным лингвокультурам и различным коммуникативным средам. Материалом для анализа в рамках данной статьи послужили франкоязычные научные тексты из области юрислингвистики и их переводы на русский язык. Поскольку эти тексты содержат размышления о различных аспектах юридической деятельности, в частности о переводе юридических текстов, их можно отнести к метаюридическому дискурсу.

Возможности анализа франкоязычных научных текстов с использованием понятия эпистемической ситуации с опорой на концепцию переводческого пространства покажем на примере перевода фрагмента статьи «Décalages et interférences en traduction juridique espagnol-français» (Setty, 2002) с французского языка на русский.

\section{Оригинал:}

Tout autant qu'une affaire de langue, la traduction est dès lors affaire de droit comparé car il s'agît avant toute de rendre les concepts et institutions juridiques sous-jacents. C'est dans ce sens que l'on parle de bi-linguisme (langue française-langue espagnole) et de bi-juridisme (droit français - droit espagnol) toujours abordés au niveau des équivalences (Setty, 2002, p. 52). 
Проанализируем представленную в данном фрагменте эпистемическую ситуацию. Ее центром, или онтологическим ядром, является терминосистема, в данном тексте мы наблюдаем порождение нового термина: bi-juridisme (би-правовая система, би-юридическая система), образованного по аналогии с известным термином bi-linguisme (билингвизм, двуязычие). Как видим, онтологический аспект эпистемической ситуации тесно переплетается с методологическим аспектом, поскольку данный термин имеет существенное методологическое значение, раскрывая сложности перевода специального юридического текста, где наряду с лингвистическими барьерами переводчику необходимо преодолевать специальные юридические барьеры. Кроме того, рассматриваемое терминосочетание имеет определенный аксиологический статус, так как автор текста акцентирует внимание читателя на том, что достижение эквивалентности при переводе юридических текстов зависит, прежде всего, от учета юридических факторов. Новизна авторского подхода состоит не только в использовании им нового термина, но и в неоднократном подчеркивании необходимости его введения, а главное, оценивания юридических знаний принимающей культуры, без которых качественный перевод невозможен. В связи с этим автор использует такие речевые единицы, как: tout autant que; car il s'agît avant tout de; c'est dans ce sens que l'on parle de (настолько же как...; так как речь идет, прежде всего о...; именно в этом смысле говорят о...), отражающие аксиологический компонент. Уточним, что онтологический компонент представлен терминами: traduction concepts et institutions juridiques, bi-linguisme, bi-juridisme, équivalences. Методологический компонент нашел отражение в следующих фразах: toujours abordés au niveau des éqivalences; c'est dans ce sens.

Как было показано выше, в русскоязычном научном тексте реализуется кольцевая индуктивно-дедуктивная структура смысла. По нашим наблюдениям, аналогичная структура вычленяется и в тексте на французском языке: ....une affaire de langue, la traduction est dès lors affaire de droit comparé.
Перевод:

Выступая результатом лингвистической деятельности, перевод юридических текстов становится также результатом деятельности в области межъязыкового и межкультурного сопоставительного права, так как речь идет, прежде всего, о необходимости передать соответствующие юридические концепты и структуры. Именно в этом смысле можно говорить о би-лингвистической (французский язык - испанский язык) и би-юридической системах (французское право - испанское право), которые анализируются с целью достижения эквивалентности.

В тексте перевода, как и в оригинале, эпистемическая ситуация основывается на термине «перевод», обладающем обобщающим значением, «запускающим» дедуктивноиндуктивный механизм порождения смысла. Констатируем, что от общего понятия «перевод» автор текста (как и автор перевода), переходит к дифференцированным понятиям: «би-лингвистическая система», «би-юридическая система». Далее в тексте происходит новое обобщение - успешное функционирование этих систем обусловливает достижение переводческой эквивалентности, в результате чего формируется дедуктивная эпистемическая ситуация.

Подытоживая, подчеркнем, что успешная трансляция переводчиком заданной эпистемической ситуации с сохранением дедуктивно-индуктивного способа формирования и формулирования мысли приводит его к гармоничному переводу.

Важно, что понятие эпистемической ситуации помогает представить и описать ход мысли переводчика как познающего субъекта, активного участника познавательной деятельности.

\section{Заключение}

Завершим наши рассуждения об индуктивном и дедуктивном путях познания в научном дискурсе наблюдением о том, что коммуникативная сторона научного знания, ориентированная на взаимодействие автора и читателя, предъявляет свои требования к содержанию научного текста. Единство аспектов содержания научного текста 
закреплено терминологически как эпистемическая ситуация.

Эпистемическая ситуация - это единица содержания, или научное знание, которое охватывает информацию о предмете, методе получения этой информации, ценностной ориентации автора текста. Эпистемическая ситуация проявляется в тексте в единстве трех компонентов: онтологического (предмет), методологического (метод), аксиологического (ценностная ориентация).

В рамках эпистемической ситуации мы проанализировали индуктивный и дедуктивный пути познавательного процесса и выявили их воплощение в тексте в виде «кольцевой структуры», предполагающей движение от общего, дедуктивного утверждения к частным, индуктивным, а затем дальнейшее обобщение, в результате которого формируется дедуктивная эпистемическая ситуация, что проиллюстрировано на материале русскоязычных теоретических текстов.

Аналогичные результаты получены при анализе переводного дискурса, в частности при сопоставлении текстов переводов с французского языка на русский. Осознавая расхождения в актуализации рече-текстовых единиц в системах переводного и непереводного дискурсов, мы установили, что «дедуктивно-индуктивное кольцо» как отражение абстрактной эпистемической ситуации полностью сохранено в анализируемом тексте, что позволяет, во-первых, констатировать, порождение гармоничного текста перевода, во-вторых, выдвинуть гипотезу о том, что выявление переводчиком научного текста эпистемической ситуации, вербализуемой в виде определенных рече-текстовых единиц, может стать одним из объективных критериев гармоничного перевода, что обеспечит порождение и функционирование качественного переводного дискурса.

\section{СПИСОК ЛИТЕРАТУРЫ}

Введение в синергетику перевода, 2014. Под общ. ред. Л. В. Кушниной. Пермь : Изд-во Перм. нац. исслед. политехн. ун-та. 278 с.

Данилевская Н. В., 2005. Роль оценки в механизме развертывания научного текста. Пермь : Изд-во Перм. ун-та. 145 с.
Кожина М. Н., 2002. Речеведение и функциональная стилистика: вопросы теории. Избранные труды. Пермь : Перм. ун-т, ПСИ, ПССГК. 475 с.

Котюрова М. П., 1988. Об экстралингвистических основаниях смысловой структуры научного текста (Функционально-стилистический аспект). Красноярск : Изд-во Краснояр. ун-та. $171 \mathrm{c}$.

Котюрова М. П., 2011. Репрезентация эпистемического кода в научном тексте // Коммуникация в поликодовом пространстве: языковые, культурологические и дидактические аспекты : тез. докл. междунар. науч.-практ. конф. (СанктПетербург, 11-13 мая 2011 г.). СПб. : Изд-во Политехн. ун-та. С. 145-146.

Котюрова М. П., 2013. Речевая системность (к развитию понятия) // Стереотипность и творчество в тексте / под ред. проф. М. П. Котюровой. Пермь : Перм. ун-т. Вып. 17. С. 27-44.

Котюрова М. П., 2014. Русский язык: «чекан» научного текста // Лингвистика. Семиотика. Метапоэтика : науч. сб. / под ред. д-ра филол. наук В. П. Ходуса. Ставрополь : СКФУ : Дизайн-Студия Б. Вып. 1 (14). С. 123-129.

Котюрова М. П., Баженова Е. А., 2007. Культура научной речи: текст и его редактирование. Пермь : Ред.-изд. отд. Западно-Уральского инта экономики и права. 281 с.

Котюрова М. П., Соловьева Н. В., 2017. Современный научный текст (сквозь призму дискурсивных изменений). Пермь : ПГНИУ. 204 с.

Котюрова М. П., Тихомирова Л. С., Соловьева Н. В., 2011. Идиостилистика научной речи: наши представления о речевой индивидуальности ученого. Пермь : Ред.-изд. отдел ЗападноУральского ин-та экономики и права. 393 с.

Кушнина Л. В., 2009. Теория гармонизации: опыт когнитивного анализа переводческого пространства. Пермь : Изд-во Перм. гос. техн. ун-та. 196 с.

Новиков А. И., 1983. Семантика текста и его формализация. М. : Наука. 216 с.

Падучева Е. В., 2006. Наблюдатель: типология и возможные трактовки // Компьютерная лингвистика и интеллектуальные технологии : тр. Междунар. конф. «Диалог-2006» (Бекасово, 31 мая - 4 июня 2006 г.) / под ред. Н. И. Лауфер, А. С. Нариньяни, В. П. Селегея. М. : Изд-во РГГУ. С. 403-414.

\section{ИСТОЧНИКИ}

Бондарко А. В., 2002. Теория значения в системе функциональной грамматики: на материале русского языка. М. : Языки славянской культуры. 736 с. 
Кожина М. Н., 2015. Об отношении стилистики к лингвистике текста // Стереотипность и творчество в тексте : межвуз. сб. науч. тр. / под ред. проф. М. П. Котюровой. Пермь : Перм. ун-т . Вып. 19. С. 5-18.

Рябцева Н. К., 2005. Язык и естественный интеллект. M. : Academia. $640 \mathrm{c}$.

Setty A. M., 2002. Décalages et interprétations en traduction juridique espagnol-francais // ILCEA, Revue de l'Institut des langues et cultures d'Europe, Amérique, Afrique, Asie et Australie. Vol. 3. P. 51-69.

\section{REFERENCES}

Kushnina L.V., ed. 2014. Introduction to translation synergetics. Perm, Izd-vo Perm. nats. issled. politekhn. un-ta. $278 \mathrm{p}$.

Danilevskaya N.V., 2005. The role of assessment in the mechanisms of academic text expansion. Perm, Izd-vo Perm. un-ta. $145 \mathrm{p}$.

Kozhina M.N., 2002. Speech studies and functional stylistics: theoretical issues. Selected works. Perm, Perm. un-t, PSI, PSSGK. 475 p.

Kotyurova M.P., 1988. On the extralinguistic foundations of the meaning structure of academic text (functional and stylistic aspect). Krasnoyarsk, Izd-vo Krasnoyar. un-ta. 171 p.

Kotyurova M.P., 2011. Representation of epistemic code in the academic text. Kommunikatsiya $v$ polikodovom prostranstve: yazykovye, kulturologicheskie $i$ didakticheskie aspekty: tez. dokl. mezhdunar. nauch.-prakt. konf. (Sankt-Peterburg, 11-13 maya 2011 g.). Saint Petersburg, Izd-vo Politekhn. un-ta, pp. 145-146.

Kotyurova M.P., 2013. The systemic nature of speech (on the development of the concept). Stereotipnost i tvorchestvo v tekste. Perm, Perm. un-t Publ., iss. 17, pp. 27-44.

Kotyurova M.P., 2014. The Russian language - the "dresser" of the academic text. Lingvistika. Semiotika. Metapoetika: nauch. sb. Stavropol,
SKFU; Dizayn-Studiya B Publ., iss. 1 (14), pp. 123-129.

Kotyurova M.P., Bazhenova E.A., 2007. The culture of academic speech. Text and its editing. Perm, Red.-izd. otd. Zapadno-Uralskogo in-ta ekonomiki i prava. $281 \mathrm{p}$.

Kotyurova M.P., Solovyeva N.V., 2017. Modern academic text (through the prism of discourse changes). Perm, PGNIU Publ. 204 p.

Kotyurova M.P., Tikhomirova L.S., Solovyeva N.V., 2011. Idiostylistics of academic speech. Our assumptions of a scientist's speech individuality. Perm, Red.-izd. otdel Zapadno-Ural'skogo in-ta ekonomiki i prava, 2011.393 p.

Kushnina L.V., 2009. Theory of harmonization: experience of cognitive analysis of translation space. Perm, Izd-vo Perm. gos. tekhn. un-ta. $196 \mathrm{p}$.

Novikov A.I., 1983. Text semantics and its formalization. Moscow, Nauka Publ. $216 \mathrm{p}$.

Paducheva E.V., 2006. Observer: typologies and possible interpretations. Kompyuternaya lingvistika i intellektualnye tekhnologii: $t r$. Mezhdunar. konf. «Dialog-2006» (Bekasovo, 31 maya - 4 iyunya 2006 g.). Moscow, RGGU Publ., pp. 403-414.

\section{SOURCES}

Bondarko A.V., 2002. The theory of meaning in the system of functional grammar. Moscow, Yazyki slavyanskoy kultury Publ. $736 \mathrm{p}$.

Kozhina M.N., 2015. On the relation of style to text linguistics. Kotyurova M.P., ed. Stereotipnost $i$ tvorchestvo v tekste: mezhvuz. sb. nauch. tr. Perm, Perm. un-t Publ., iss. 19, pp. 5-18.

Ryabtseva N.K., 2005. Language and Human Mind. Moscow, Academia Publ. 640 p.

Setty A.M., 2002. Décalages et interprétations en traduction juridique espagnol-francais. ILCEA, Revue de l'Institut deslangues et cultures d'Europe, Amérique, Afrique, Asie et Australie, vol. 3, pp. 51-69.

\section{Information about the Authors}

Mariya P. Kotyurova, Doctor of Sciences (Philology), Professor, Department of Russian Language and Stylistics, Perm State University, Bukireva St., 15, 614990 Perm, Russia, kotyurova@yandex.ru, https://orcid.org/0000-0001-5418-726X

Lyudmila V. Kushnina, Doctor of Sciences (Philology), Professor, Department of Foreign Languages, Linguistics and Translation, Perm National Research Polytechnic University, Prosp. Komsomolsky, 29, 614900 Perm, Russia, lkushnina@yandex.ru, https://orcid.org/0000-0003-4360-7243 


\section{Информация об авторах}

Мария Павловна Котюрова, доктор филологических наук, профессор кафедры русского языка и стилистики, Пермский государственный национальный исследовательский университет, ул. Букирева, 15, 614990 г. Пермь, Россия, kotyurova@yandex.ru, https://orcid.org/0000-0001-5418-726X

Людмила Вениаминовна Кушнина, доктор филологических наук, профессор кафедры иностранных языков, лингвистики и перевода, Пермский национальный исследовательский политехнический университет, просп. Комсомольский, 29, 614990 г. Пермь, Россия, lkushnina@yandex.ru, https://orcid.org/0000-0003-4360-7243 